\title{
Storytelling in Jazz Work as Retrospective Collaboration
}

\author{
FUMI OKIJI
}

\begin{abstract}
Storytelling has proved to be a useful metaphor in jazz commentary and analysis. Within such literature it is invariably solos, portrayed as discrete cultural articles, that "tell a story" through their adherence to internal coherence and logic. This prized autonomy is modeled on that which we find in the modern European tradition. Pathbreaking studies by scholars such as Ingrid Monson, Paul Berliner, and Keith Sawyer have redressed this hegemony in highlighting the importance of collaborative work in jazz. This essay needs to be considered a contribution to this focus. Yet approaches that emphasize interaction among band members tend toward dialogical metaphors and analytical frameworks that marginalize forms of creative "collaboration" that can occur retrospectively between musicians and vocalists who may not have even met. Drawing from Walter Benjamin's essay "The Storyteller: Nikolai Leskov," this essay argues that storytelling in jazz is an intergenerational, accumulative effort in which we see a story continue to unfold with each new telling. It shows that there is generative tension between a musician holding on to his or her distinctive characteristics and approach, and their commitment to sharing (in) the story. Storytelling in jazz involves musicians adding "transparent layers" to the tradition, contributing to musical material, and collaborating with others (both contemporary and temporally distant) in a manner in which personal distinction is actively maintained. Through a consideration of John Coltrane's ideas concerning the centrality of community to the practice, storytelling in jazz is shown to be of extramusical social significance also.
\end{abstract}

$[\mathrm{T}]$ hat slow piling one on top of the other of thin, transparent layers ... constitutes the most appropriate picture of the way in which the perfect narrative is revealed through the layers of a variety of retellings.

—Walter Benjamin ${ }^{1}$

There is no singing in parts, as we understand it, and yet no two appear to be singing the same thing - the leading singer starts the words of each verse, often improvising, and the others, who "base" him, as it is called, strike in with the refrain, or even join in the solo, when the words are familiar. When the "base" begins, the leader often stops, leaving the rest of his words to be guessed at, or it may be they are taken up by one of the other singers. And the "basers" themselves seem to follow their own whims, beginning when they please and leaving off when they please, striking an octave above or below ... or hitting some other note that chords, so as to produce the effect of a marvelous complication and variety, and yet with the most perfect time, and rarely with any discord. And what makes it harder to unravel a thread of melody out of this strange network is that, like birds, they seem not infrequently to strike sounds that cannot be precisely represented by the gamut,

I would like to thank Andrew Bowie, Daniel Matlin, Jon Hughes, and Jonathan Impett for their feedback on various aspects of this article. I am also grateful to the two reviewers for their interest and comment. The article is drawn from research funded by the Arts and Humanities Research Council, UK.

${ }^{1}$ Walter Benjamin, “The Storyteller: Reflections on the Works of Nikolai Leskov," in Illuminations: Essays and Reflections, ed. Hannah Arendt, trans. Harry Zohn (London: Fontana, 1992), 92. 
and abound in "slides from one note to another, and turns and cadences not in articled notes."

—William Francis Allen ${ }^{2}$

To "tell a story," and particularly to "tell your story," is the well-worn advice for building a successful jazz solo. Trumpeter and vocalist Doc Cheatham tells us, "If a guy plays a beautiful solo and he's playing from the heart or he's talking with his horn, we say, 'He's telling a story."'3 Pianist Fred Hersch insists, "the best jazz ... is musical storytelling in real time," while Lester Young's admonition to young musicians, "You're technically hip ... But what is your story?," highlights the importance of the individual voice to the practice. ${ }^{4}$ According to Brian Harker, "telling a story" is a "folksy expression" that takes in "less quantifiable elements ... such as personality traits [of musicians] and cultural resonances. But purely musical coherence may be more fundamental." 5 The notion that storytelling in jazz is principally concerned with the "syntactic continuity and cumulative development" of individual solos is a popular one in jazz studies. It is an idea that finds support in areas of the discipline associated with more traditional methods of musical analysis. ${ }^{7}$ The pervasiveness of this sense of storytelling, which is corroborated, albeit in often more ambivalent fashion, by many musicians, has meant that it has gone largely unchallenged even from quarters that have been instrumental in upsetting other hegemonic strangleholds in the studies.

The pioneering work by scholars such as Ingrid Monson, Paul Berliner, and Keith Sawyer has been crucial in redressing analytical focus away from the individual solo and in highlighting the importance of collaborative work in jazz. ${ }^{8}$ As a corrective to the overwhelming focus on solos, these writers have encouraged us to consider dialogue and conversation as frameworks through which to analyze jazz performance. They have shown the underexplored rhythm section to be much more than relief against which great solos are spun. The contributions of all participating musicians are valued, and their interaction is considered to be of utmost importance to the success of their work. The jazz band is presented as a socio-musical practice in which interlocution is at least as important as oratory.

\footnotetext{
${ }^{2}$ William Francis Allen, quoted in Shane White and Graham White, The Sounds of Slavery: Discovering African American History Through Songs, Sermons, and Speech (Boston: Beacon, 2005), 63-64.

${ }^{3}$ Paul Berliner, Thinking in Jazz: The Infinite Art of Improvisation (Chicago: University of Chicago Press, 1994), 255.

${ }^{4}$ Gabriel Solis, "Hearing Monk: History, Memory, and the Making of a 'Jazz Giant,"' Musical Quarterly 86, no. 1, (2002): 95; Robert G. O’Meally, "Response" to Nellie McKay, "Biography and Afro-American Culture," in Afro-American Literary Study in the 1990s, ed. Houston Baker and Patricia Redmond (Chicago: University of Chicago Press, 1989), 221. Emphasis in original.

${ }^{5}$ Brian Harker, Louis Armstrong's Hot Five and Hot Seven Recordings (New York: Oxford University Press, 2011), 41. Emphasis added.

${ }^{6}$ Ibid.

${ }^{7}$ See, for instance, Gunther Schuller, Musings: The Musical Worlds of Gunther Schuller (New York: Oxford University Press, 1989).

${ }^{8}$ Ingrid Monson, Saying Something: Jazz Improvisation and Interaction (Chicago: University of Chicago Press, 1996); Berliner, Thinking in Jazz; Keith R. Sawyer, "Improvisational Cultures: Collaborative Emergence and Creativity in Improvisation," Mind, Culture, and Activity 7, no. 3 (2000): $180-85$.
} 
The present essay contributes to this focus, but through an extension of Daniel Oakland's tentative ideas concerning how the tradition allows (and perhaps, calls for) intergenerational, retrospective collaboration between players (both those dead and those alive), it reforms Monson's sketch of intermusicality to take in a broader notion of jazz work. The ideas I will present are enabled by Walter Benjamin's essay "The Storyteller: Reflections on the Works of Nikolai Leskov." In it the theorist explores how new versions of a story repeat what has already been given, but do so in a way that retains each teller's perspective and personal quirks. ${ }^{9}$ Benjamin refers to each re-telling as a "transparent layer." This transparency is crucial to a full appreciation of the insight because it suggests that past efforts have not been covered over or surpassed by new ones, but are retained and are in fact reanimated (re-worked) by the more recent. By way of Benjamin's framework, I imagine hearing the performances of "Body and Soul" I am most familiar with played all at once. I hear unmistakable voices (of John Coltrane, Archie Shepp, Dexter Gordon, Billie Holiday, and Betty Carter, to name a few); weaving towards and away from each other creating chords of varying degrees of dissonance/consonance; alternately taking the lead as the chorus "bases"; at times providing supportive, unifying accompaniment, and at others allowing individual voices to stand in stark contrast to what is being sounded around them. "Body and Soul" is the ever-forming story that the musicians retell. ${ }^{10}$ In conceptualizing jazz work as a conglomeration or gathering in difference (and often in deviation), I am able to assert that wanting to contribute to the story but in one's own voice is a key imperative in jazz. ${ }^{11}$

This essay is emboldened by Vijay Iyer's challenge to both contract and dilate the analytical focus we use when considering jazz in order to capture registers that tend to evade conventional means of analysis-both the microscopic details of individual practice and the broader temporally (and spatially) dispersed musical moments

\footnotetext{
${ }^{9}$ Benjamin, “The Storyteller." See also Andrew Benjamin, Present Hope: Philosophy, Architecture, Judaism (Hove: Psychology, 1997), 55; and Rajeev S. Patke, "Benjamin on Art and Reproducibility: The Case of Music's Reproducibility," in Walter Benjamin and Art, ed. Andrew Benjamin (London: Continuum, 2005), 196.

${ }^{10}$ See Jose Bowen's exhaustive documentation of interpretative innovation in the recorded history of the standard "Who Plays the Tune in 'Body and Soul'? A Performance History Using Recorded Sources," Journal of the Society for American Music 9, no. 3 (2015): 259-92; and Cynthia Folio and Alexander Brinkman, "Dexter Gordon's Ultimate 'Body and Soul," in Five Perspectives on "Body and Soul" and Other Contributions to Music Performance Studies, ed. Claudia Emmenegger and Oliver Senn, 45-60, Proceedings of the "International Conference on Music Performance Analysis," Lucerne, Switzerland, 1-2 July 2009 (Zurich: Chronos, 2011).

${ }^{11}$ I have used the word "jazz" with deep misgiving as to its suitability. For a start, it is imbued with concepts that assisted in the racialization of Africans in the United States (consider, for instance, its etymological foundation in the word "jass" and its associated sexual connotation). Also, where "jazz" intimates generic boundaries and practices enclosure, it does not lend itself to my interest in the music as a part of a broader expressive continuum, where all expressive work is structured through the play between communion and particularity. I have considered following the lead of musicians such as Duke Ellington and the Art Ensemble of Chicago, who eschew the heavily loaded term in favor of one reflective of the music's generic ambivalence and one also capable of highlighting its socio-historical specificity. "Negro Music" and "Great Black Music" also carry much baggage and do not have the luxury of a history of largely unreflective use on their side. I have settled on the no less contentious but more broadly accepted term.
} 
through which the tradition is "played." 12 I will show how storytelling, when understood as a shared reiterative undertaking (an endless, boundless rehearsal) involving a collective of disparate, living and deceased participants, can bring to light endlessly evolving sites of expressive and cultural significance. Storytelling can be seen at work in any number of ways: in a solo musician's relationship with a particular composition (for instance, in Thelonious Monk's reiterative practice-performance of "I'm Getting Sentimental Over You" and the numerous live and studio performances of his composition "Ruby, My Dear"); ${ }^{13}$ through temporally dispersed performances of a standard by various contributors; through accumulating exploration of musical expression that breaks into the verbal such as screaming; in how significant recurring words such as "body" and "soul" register in contributions from instrumentalists as well as vocalists; and through how spiritual incantation travels from the church through the musical tradition and back again. As I hope is clear, these are but a very small sample of possible sites of significance. Stephen Henderson calls these shared nodes "mascons" or "massive concentrations" of "experiential energy," and in the absence of a term currently being used within the studies that can capture the various and combining expressive registers and ensemble configurations, I will use it when to use "story" would create confusion. ${ }^{14}$ Within my theoretical elucidation, the term "story" is generally used to ensure that my ideas are understood within the context of wider discussions.

Crucial groundwork to this alternative analytic is an appreciation of the generative tension between a musician holding on to their distinctive characteristics and approach, and their commitment to sharing (in) the story. It needs to be stressed that what is suggested here is not a conception of jazz bled of the particularity of the individual musician. What is being speculatively presented is an understanding of jazz as an empathetic way of playing together and alongside each other. It is one in which, together with technical proficiency and the ability to respond critically to other musicians and the tradition, is the creative work involved in fulfilling a desire to work toward something communal, but in one's own voice. The work of a jazz musician involves negotiating an ever-adjusting gravitational pull toward the tradition (its musical material and collaborators, those alive and those who have passed). Most broadly, to play jazz is to re-tell the story of the jazz tradition but to do so in one's own voice.

The essay proceeds from a survey of the metaphoric use of storytelling and other forms of verbal communication, such as conversation. I expand on the notion of storytelling as the production of successful solos, before considering how scholars

${ }^{12}$ Vijay Iyer, "Exploding the Narrative in Jazz Improvisation," in Uptown Conversation: The New Jazz Studies, ed. Robert G. O’Meally, Brent Hayes Edwards, and Farah Jasmine Griffin (New York: Columbia University Press, 2004), 393-403.

${ }^{13}$ I have Fred Moten to thank for drawing my attention to this practice-performance included on the 2007 Monk collection, The Transformer.

${ }^{14}$ Stephen Henderson, Understanding the New Black Poetry: Black Speech and Black Music as Poetic References (New York: William Morrow, 1973), 44. I have omitted the "black" from Henderson's description, as there is not the time nor space in the present essay to defend what would otherwise be seen as an unjustifiably limiting descriptor. As a literary theorist, Henderson was referring primarily to written text, although his is a broad understanding of the black poetic tradition and included blues, spirituals, and work song in his study. 
such as Ingrid Monson have presented interlocution as a more faithful description of what occurs within performance. An engagement with Iyer's "Exploding the Narrative in Jazz Improvisation" sets the foundation for a reconsideration of storytelling as a useful conceptual device. In this section I show the story to be an ideal tool with which to consider collaborative work, both that within the musical tradition, and that between the music and the communities from which it has emerged. Through a consideration of John Coltrane's thoughts on jazz and community contained in a letter he sent to Down Beat editor Don DeMicheal in 1962, I suggest that storytelling in the practice occurs on a broad social plane. In the section entitled "Layering, listening, mimesis," I explicate the theoretical sketches presented in this introduction and show storytelling to be a way to understand fundamental principles of jazz work. Here I consider the layering or collective reiteration of stories/mascons; the mimetic negotiations called upon in order to play or sing along with other participants while nurturing distinction; and finally, the pertinence of listening within jazz practice, which considered more than a passive, secondary activity and is, in fact, essential to embodiment and sharing in storytelling.

\section{Storytelling and Jazz in the Studies}

\section{"Telling a story" as Internal Coherence}

There is discrepancy between this sketch of inter-generational musical collaboration and what is considered to be storytelling in much music scholarship. As the opening paragraph highlights, scholars use the word "story" most often as a metaphor to emphasize the internal coherence of a discrete cultural product with a beginning, middle, and end. The story unfolds logically. Happenings are often recalled consecutively, or at least with an expectation that all the requisite parts "make sense" by the end of the telling. Its parts anticipate the completion of the piece; they assume that the story can be complete. Rather than an accumulative effort in which we see the amplification of the story with each new telling, as Benjamin posits, in jazz studies "the story" tends to start and be completed within a single solo. The success of a solo is seen as wrapped up in its internal logic, a hermetic pursuit modeled on the modern European tradition. ${ }^{15}$ The solo and the individual musician are the focal point in the jazz narrative. In this understanding, little or no consideration is given to the very particular practices associated with storytelling communities.

The painstaking ethnographic document of the jazz musician's life, particularly the focus on musicians' own thoughts on the creative and analytical practices involved in playing jazz music, make Paul Berliner's Thinking in Jazz an important contribution to the 1990 s cultural turn within jazz studies. ${ }^{16}$ Perhaps the most significant disciplinary development that has occurred as a consequence of his

\footnotetext{
${ }^{15}$ For instance, Gunther Schuller, "Sonny Rollins and the Challenge of Thematic Improvisation," Jazz Review 1, no. 1 (1958): 6-11. Also see comments on Thelonious Monk by Martin Williams in The Jazz Tradition (New York: Oxford University Press, 1993), in which he writes, "the highest tribute I have ever heard paid to Monk's music ... [is that] Monk seems to finish things" (159).

${ }^{16}$ Berliner, Thinking in Jazz.
} 
study has been that greater attention has been paid to the interaction that takes place among members of a band during performance. The study has been foremost in attempts to redress the focus away from individual solos and "great man of jazz" narratives, toward what is undeniably a more faithful portrayal of the music as the creative play of a group of musicians. It suggests a practice in which collaborative creation is as important as the genius of the melodist. It shows an appreciation of the negotiations between the individual and his musical community as pertinent to a more comprehensive understanding of jazz. In relation to storytelling, Thinking in Jazz shares musicians' insight into what the term means to them, alongside commentary on jazz solos, to show "the story" to be a useful discursive tool. And yet it is clear, particularly in the insightful analysis of Miles Davis's solo on "Blues by Five," that Berliner's model of storytelling can be traced to what Iyer calls the "Schulleresque narrative arc." 17 A story is confined to an individual solo and most often refers to its linearity and inner coherence. For Berliner, storytelling in jazz has to do with the "dramatic molding of creations to include movement through successive events 'transcending' particular repetitive, formal aspects of the composition." ${ }^{18}$ As Morris Holbrook points out, Berliner, among others (he also names Steve Larson and André Hodeir), consider an "improviser [successful] in telling a story ... when the relevant elements combine seamlessly and cohere convincingly to build meaningfully." ${ }^{\prime 19}$ This teleological understanding of storytelling is common.

Gunther Schuller, writing on the development of Lester Young's style, suggests that the blues is a paradigmatic "linear concept of playing and singing." We are told that "It has to be, and it always was. It had to be because it is a narrative form of expression. It is essentially a vocal tradition; it tells a story." ${ }^{20}$ Similarly, Scott DeVeaux tells us that Coleman Hawkins's "way of 'telling a story'... was uncomplicated and emotionally direct" but continues in a somewhat contradictory vein, describing Hawkins's improvisation as "a continuous, carefully controlled crescendo of intensity on several fronts at once. ... The relentless linear logic of harmonic improvisation served as the connecting thread." ${ }^{11}$ While it is not my intention to argue that there is no linearity in the blues, or jazz for that matter, the suggestion that forms that are so dependent on repetition and cyclical movement can be considered as principally linear seems, at best, incomplete. The error of this misalignment is compounded by the attempt to explain the alleged linear character by pointing to the form's orality, when, in fact, that is an important reason to question it. The notion that a story is started and completed by a single solo fails to

${ }^{17}$ This term was used by Iyer in Exploding the Narrative, 394. Berliner has much to say about the use of "quotation" (that is the borrowing of musical phrases, sometimes entire solos, from other musicians) for pedagogical purposes and for use during a musician's apprenticeship. He acknowledges its wider use within jazz but there is often the sense that it is a poor substitute to the rendering of "original" melody.

${ }^{18}$ Berliner, Thinking in Jazz, 201.

${ }^{19}$ Morris Holbrook, Playing the Changes on the Jazz Metaphor: An Expanded Conceptualization of Music, Management, and Marketing-Related Themes (Boston: Now Publishers, 2008), 112.

${ }^{20}$ Gunther Schuller, The Swing Era: The Development of Jazz, 1930-1945 (New York: Oxford University Press, 1991), 548.

${ }^{21}$ Scott DeVeaux, The Birth of Bebop: A Social and Musical History (Berkeley: University of California Press, 1997), 97-98. 
account for the communal nature of oral traditions, of which storytelling must be considered a prime example. Much of what is written pertaining to the story-like qualities of jazz appears to be describing something closer to the solitary experience of the novel. Paul Wertico in an interview with Berliner suggests this when he says, "The real great cats can write novels." 22 On these accounts one would believe that the story metaphor "simply mean[s] that a [solo] must have a logical structure, a beginning, middle, and conclusion, melodically and harmonically." ${ }^{23}$ Yet treating stories in jazz as discrete entities with each solo (invariably, the story is contained in a solo) being considered in isolation creates a tendency to ignore other significant dialogic and heterophonic relationships. Despite suggestions of autonomy and the preeminence of internal logic, along the lines often taken as given for assessing works of the modern European tradition, storytelling in jazz is also, and arguably primarily, of a communal nature.

\section{Not Storytelling, Conversation}

Paul Berliner and Ingrid Monson are often cited together as the foremost authorities on the significance of linguistic metaphors in jazz studies. ${ }^{24}$ While Monson's work on interlocution and antiphony in jazz is extremely useful as a coherent argument in support of the central importance of interaction and dialogism in the music, her book Saying Something only sparingly engages with storytelling. In fact, in the form in which it is cast in a great deal of jazz commentary, storytelling appears to have much less than conversation to offer Monson's thesis concerning the primacy of collective creative practice in jazz. In order to put across the real-time interaction of jazz ensembles, improvisational open-endedness, and "stylistic and affective aspects," Monson showcases conversation as a metaphor par excellence. ${ }^{25}$ She writes:

In jazz improvisation ... all of the musicians are constantly making decisions regarding what to play and when to play it, all within the framework of a musical groove, which may or may not be organized around a chorus structure. The musicians are compositional participants who may "say" unexpected things or elicit responses from other musicians. Musical intensification is open-ended rather than pre-determined and highly interpersonal in character-structurally far more similar to a conversation than to a text. ${ }^{26}$

The story as internal coherence cannot allow for the banter, extrapolation, "signifying," and chorusing that many commentators take to be distinctive of African American music. Storytelling as internal coherence does not take account of the importance of listening or of the audience and its collaborative effort in the creation of

${ }^{22}$ Berliner, Thinking in Jazz, 202.

${ }^{23}$ Buck Clayton quoted in Douglas H. Daniels, "Lester Young: Master of Jive," American Music 3, no. 3 (1985): 318.

${ }^{24}$ For precursory considerations, see Samuel Floyd, The Power of Black Music: Interpreting Its History from Africa to the United States (New York: Oxford University Press, 1995), which views the issue from an Afrological perspective with special attention to African retentions. See also Paul Rinzler, "Preliminary Thoughts on Analyzing Musical Interaction Among Jazz Performers," Annual Review of Jazz Studies 4 (1988): 153-60.

${ }^{25}$ Monson, Saying Something, 73.

${ }^{26}$ Monson, Saying Something, 81, my emphasis. Interestingly, Monson draws from Mikhail Bakhtin's (2010) Dialogic Imagination: Four Essays (Austin: University of Texas Press, 1982), which arguably brings her closer to a particular formulation of the novel form. 
“works.” As Keith Sawyer, in line with Monson, maintains, “Jazz is fundamentally an ensemble art form, and everyone involved in the improvisation is constantly offering new ideas - "tentative moves, slight variations" - and each musician is listening closely to the others. The performance that results is truly a group creation, a collective social process." 27

This focus on interaction and collaborative practice has proved to be an important and well-received redress from the dominance of approaches in which the soloist is seen to embody what is essential to jazz. ${ }^{28}$ Rather than analyses in which the soloist's melodic line is transcribed and placed against the context of a rudimentary representation of the "accompaniment," often just chord symbols, we find musicologists paying greater attention to the role of the rhythm section. As well as conventional scores that detail the accompaniment the rhythm section provides, there has been greater use and the development of new, complementary graphic devices. ${ }^{29}$ For instance, "intuitive schematic diagrams" that chart the intensity of an improvisation encourage the consideration of aspects other than harmony and melody (although their use does suggest retention of the traditionalist preoccupation with development and progress of an unfolding piece or solo). While not usurping the melodic line as the prime site of interest, the complex represented in the transcription of bass, drums, and piano has helped effect a shift from the assumption that the linear narrative of the soloist is the polestar of jazz performance, toward a deeper appreciation of the form's antiphonic underpinnings.

However, the attention paid to conversation as a metaphor and tool for understanding the creative processes of jazz has been at the expense of the discipline's engagement with other types of interaction. Alongside antiphony are certain polyphonic and heterophonic ways of working together, which are arguably as important but have been largely ignored. This oversight and the limitations it poses for thinking through interaction in improvised music has been discussed by David Borgo and Jeff Kaiser. They write that "the notions of interaction and interactivity subsumeoften in rather vague ways - an enormous variety of embodied, interpersonal, and human-computer dynamics. In the discourse surrounding improvised music, for instance, the term interaction still often brings to mind metaphors of conversation, vocabulary and other aspects of language that, while perhaps well suited to analyzing more conventional forms of jazz improvisation, are often ill suited to describe more contemporary performance practices." ${ }^{30}$ Without denying the importance of

${ }^{27}$ Keith Sawyer, "Improvisational Cultures: Collaborative Emergence and Creativity in Improvisation," Mind, Culture, and Activity 7, no. 3 (2000): 180-85.

${ }^{28}$ Mark Doffman, Feeling the Groove: Shared Time and its Meanings for Three Jazz Trios (Milton Keynes: Open University Press, 2009); Peter Reinholdsson, Making Music Together: An Interactionist Perspective on Small-Group Performance in Jazz (Uppsala: Uppsala University Press, 1998); Frederick Seddon, "Modes of Communication during Jazz Improvisation," British Journal of Music Education 22, no. 1 (2005): 47-61.

${ }^{29}$ Steven Block, "'Bemsha Swing': The Transformation of a Bebop Classic to Free Jazz," Music Theory Spectrum 19, no. 2 (1997): 206-31; David Borgo, "The Play of Meaning and the Meaning of Play in Jazz," Journal of Consciousness Studies 11, no. 3-4 (2004): 174-90.

${ }^{30}$ David Borgo and Jeff Kaiser, "Configurin(g) KaiBorg: Ideology, Identity and Agency," in Proceedings of the International Conference, Beyond the Centres: Musical Avant-Gardes since 1950, Thessaloniki, Greece, 1-3 July 2010, 1. 
interlocution, I would argue the disproportionate attention that it attracts, even in "more conventional forms of jazz improvisation" has been at the expense of us considering other ways that musicians form expression together. ${ }^{31}$

\section{Jazz as Collaborative Storytelling}

Iyer challenges the idea "that the story that an improviser tells ... unfold[s] merely in the overall form of a 'coherent' solo" or "simply in antiphonal structures." He urges us to look to "the microscopic musical details ... [and] the inherent structure of the performance itself." And perhaps most crucial for this study, he stresses that the "story dwells not just in one solo at a time, but also in a single note, and equally in an entire lifetime of improvisations. In short, the story is revealed not as a simple linear narrative, but as a fractured, exploded one." ${ }^{\prime 3}$ The proposal to focus down to minute constructive detail and out to a multitude of layers that make up the "lifetime of improvisations" allows, in fact, calls for, expanded senses of both the loci of jazz work and the kinds of interaction that take place there. ${ }^{33}$ Sites of significance in jazz can be found not only within the framework provided by the individual improviser or the real-time interaction of a band, but also within the various and combining expressive registers and ensemble configurations. The gatherings of contribution (that which Stephen Henderson has termed "massive concentration[s] of ... experiential energy," or "mascons" in his writing on black poetics) ${ }^{34}$ frustrate the notion of time and space-limited collaboration we most often encounter in jazz studies. Stories are constantly being re- and deformed through and among generations of musicians. Extending Ann Beeson's thesis that "jazz" is what "the 'storytellers' tell a story about," Daniel Oakland provides a portrait of storytelling in jazz that shows the "improvisations created in the real-time of the present maintain[ing] a sense of continuity with the past." 35 These intergenerational "works" represent a markedly different version of the story from the extracted solo melody of traditional analysis. He argues that the music "does indeed recount its history with each performance." 36 Jazz is shown to be "a 'collective improvisation' in the broadest sense." 37

Intergenerational interaction in jazz work is not lost on Monson, who devotes a chapter of Saying Something to "intermusicality," which names "the particular ways in which music and, more generally, sound itself can refer to the past and offer social commentary." 38 These "musical quotations" or "allusions" create/highlight

${ }^{31}$ Ibid., 1.

${ }^{32}$ Iyer, Exploding the Narrative, 395.

${ }^{33}$ Pianist and scholar Tord Gustavsen writes of the inadequacy of approaches in which "linear aspects" dominate, and calls for analysis that is able to "switch ... between macro and micro levels" (quoted in Sven Bjerstedt, "Storytelling in Jazz Improvisation: Implications of a Rich Intermedial Metaphor," Ph.D. diss., Lund University, 2014, 66).

${ }^{34}$ Henderson, Understanding the New Black Poetry, 44.

${ }^{35}$ Ann Beeson, "Quoting Tunes: Narrative Features in Jazz," Collectanea 1 (1990), 12. Daniel Oakland, "Remembering in Jazz: Collective Memory and Collective Improvisation," Lambda Alpha Journal 28 (1998), 13. The unidentifiable colleague of Coltrane who suggests that "making the changes" of "Giant Steps" is a story in itself adds credence to the notion of self-referentiality in jazz.

${ }^{36}$ Oakland, "Remembering in Jazz," 12.

${ }^{37}$ Ibid., 15.

${ }^{38}$ Monson, Saying Something, 97. 
the collaborative space amongst musicians in real-time performance. ${ }^{39}$ For Monson, referring to past musicians is a notable antiphonic activity. Drawing from Henry Louis Gates's work on signifying (focusing particularly on the parodic and ironic dimensions of this multifaceted concept), she presents intermusicality as temporally extended conversation. ${ }^{40}$ We see this in an example she gives of performances by Coleman Hawkins and John Coltrane of "Body and Soul" in 1939 and 1960, respectively. She writes, "Playing a particular composition can ... immediately point to a prior performance, especially when the tune is a jazz standard. ... John Coltrane's recording ... transforms several dimensions of the tune: the groove, the harmony, and the melody. But merely hearing this tune played on the tenor saxophone causes the historically aware listener ... to compare the present version to prior respected performances." ${ }^{11}$ While acknowledging the validity of the dialecticism and antiphonic tension on which Monson's writing focuses, in the present discussion I am more interested in the significance of temporally distant contributions converging on a collaborative creative site such as the standard "Body and Soul." The "nonidentical iteration" (Patke) or "repetition with difference" (Gates) or "changing same" (Baraka) acknowledges the distinction of Coltrane's performance but also points to a desire to retell the standard. ${ }^{42}$ The two versions relate to each other not only by way of transformation and signification but also as two layers of the very same story. They are like two voices in a heterophonic chorus singing the same tune (the melody of which is never perfectly defined and that an analyst would struggle to notate), but with fidelity to their own vocal idiosyncrasies and performative quirks. Rather than focusing on how "transformed" Coltrane's version of the standard is, I would like to consider its interaction with Hawkins's own as a coming together of two temporally dispersed collaborators.

\section{Storytelling and Social Significance}

Jazz is highly heteronomous. Not only does it borrow from and lend itself to other genres and creative practices, but it is also a site of socio-political significance for many of its practitioners and audience-contributors. Jazz also draws from a universe of quotidian expression, and its accumulated musical material is considered by some to contain a sedimented socio-history of African America. ${ }^{43}$ This understanding

${ }^{39}$ Ibid., 97, 124.

${ }^{40}$ See also Ingrid Monson, "Doubleness and Jazz Improvisation: Irony, Parody, and Ethnomusicology," Critical Inquiry 20, no. 2 (1994): 283-313. Henry Louis Gates, The Signifying Monkey: A Theory of Afro-American Literary Criticism (New York: Oxford University Press, 1988).

${ }^{41}$ Monson, Saying Something, 98. See also Bowen, "Who Plays the Tune in 'Body and Soul'?."

${ }^{42}$ Rajeev Patke, "Benjamin on Art and Reproducibility: The Case of Music," in Walter Benjamin and Art, ed. Andrew Benjamin (London: Continuum, 2005), 196; Gates, The Signifying Monkey, 51; Amiri Baraka, Black Music: Essays (New York: Akashic, 2010), 205. It is important to make the distinction between the composition and the standard.

${ }^{43}$ Amiri Baraka's (1963) Blues People: Negro Music in White America is a prime example of this. In Conventional Wisdom: The Content of Musical Form, Susan McClary (2000) suggests that jazz's social significance is wider than the black community: "When LeRoi Jones [Amiri Baraka] published his powerful book Blues People in 1963, his title referred to the African American musicians who fashioned the blues out of their particular historical conditions and experience. Yet a music scholar of a future time might well look back on the musical landscape of the 1900s and label us all 'blues 
of jazz as thoroughly networked stands in opposition to the modern European ideal of artistic independence. In a letter to Down Beat editor Don DeMicheal in 1962, Coltrane, commenting on Aaron Copland's Music and Imagination (a book DeMicheal had recently sent him), draws a clear distinction between the musician with recourse to a community and the "American classical or semi-classical composer who has the problem, as Copland sees it, of not finding himself an integral part of the musical community." Coltrane considered community to be one of the central tenets of jazz and black expression. In a statement on the social significance of black music (and the socio-politics to which jazz work contributes), the saxophonist refers variably to the "musical community," the "hostile communities" within which the "founding fathers ... produced this music," and the "whole face of the globe [being] our community." Apart from the specific references to collective expression throughout the letter, he speaks as a communal subject, using the pronouns "we" and "our" rather than "I" and "mine." 44 There is an implication that making music, or at least making music within the jazz idiom, is inextricably bound up with extra-musical avenues of association.

An instance of this recourse to a wider community of audience-participants and social significance is revealed in an engaging passage from Vijay Iyer's essay, "Exploding the Narrative in Jazz Improvisation," which draws our attention to a conversation buried in an outtake from a 1959 recording (released the following year) of Coltrane's improvisational conundrum, "Giant Steps." ${ }^{45}$ In full appreciation of the near insurmountable challenge he had set himself and his fellow band members, Coltrane voices his concern that he may not be able to interpret the composition past "making the changes" (playing harmonically appropriate melody). Iyer writes:

\begin{abstract}
John Coltrane can be heard saying to his struggling colleagues, "I don't think I'm gonna improve this, you know... I ain't goin be sayin nothin, (I goin do) tryin just, makin the changes, I ain't goin be tellin no story... Like... tellin them black stories." Amidst the confounded mumbles of assent from his bandmates, one colleague rejoins, "Shoot. Really, you make the changes, that'll tell 'em a story." Surprised by this idea, Coltrane responds, "You think the changes're the story!" Overlapping him, a second bandmate riffs, "(Right)... that'll change all the stories (up)". His voice cracking with laughter, Coltrane admits, "I don't want to tell no lies (on 'em)." After a group laugh, the second colleague trails off in a sort of denouement, "(The) changes themselves is some kind of story (man I'm tellin you)." ${ }^{46}$
\end{abstract}

Iyer notes, "[t] $]$ hese few seconds of banter could yield a symposium's worth of exegesis," but of most interest to the discussion at hand is what Coltrane and his band show us concerning storytelling in jazz. For instance, the exchange seems to

people': those who inhabited a period dominated by blues and its countless progeny" (32-33). Key to McClary's universalizing of the blues is that it is the African American perspective through which the general socio-historical milieu is to be considered. Susan McClary, Conventional Wisdom: The Content of Musical Form. Berkeley: University of California Press, 2000.

${ }^{44}$ Coltrane quoted in Leonard Brown, "In His Own Words," in John Coltrane and Black America's Quest for Freedom, ed. Leonard Brown (New York: Oxford University Press, 2010), 17.

${ }^{45}$ Vijay Iyer, "Exploding the Narrative in Jazz Improvisation," 394. Conversation on "Giant Steps (Alternative Version)-Take 1 [Incomplete]," Heavyweight Champion-The Complete Atlantic Recordings [Disc 7], Rhino Homemade, RHM1 7784, 2000, compact disc.

${ }^{46}$ Ibid. Emphasis added. 
imply that Coltrane (the storyteller) is an integral part of a storytelling (African American) community to which he is answerable. For Coltrane, the story is not merely "making the changes" or turning out an internally coherent improvisation. Rather he suggests that some of the stories that the musicians are unable (but feel obliged) to tell would involve extramusical concerns. It is also intimated that the most pertinent story of the session was Coltrane's skillful navigation out of the maze he has constructed for himself. Moreover, the conversation encourages the view that this story should be considered a valid "black" or "community" story. The heteronomy of "Giant Steps," and jazz more broadly, is shown to work in two directions - from the expectations of the actual and imagined communities in which the musicians are embedded and from the musicians who present a story (Coltrane's cracking the "Giant Steps" code) to those communities "that'll change all the stories up."

The session presents a direct challenge to Nick Nesbitt's attempts to explain Coltrane's work through Theodor Adorno's theory of musical material. Nesbitt argues that "Coltrane constructed his music on a thorough mastery of historical musical material, and that his musical evolution was predicated upon the working through of the problems this material presented." 47 The argument is a compelling one and has much to offer by way of reinforcing the "classicizing" model of the jazz tradition. But although Nesbitt does engage in social and political context, he fails to take seriously the fact that in Coltrane's music the social and political are not mere by-products of a hermetic artistic process - the sediment of black socio-history that could not help but be present in an otherwise autonomous practice. ${ }^{48}$ The musical and extramusical communities referred to in his letter to DeMicheal were a conscious concern for Coltrane, and as such need to be considered contributors to the pool of musical material he worked through. Staying true to his proposed Adornian method, Nesbitt does not deny the socio-political in Coltrane but rather insists that its appreciation would "occur through an immersion within its extreme opposite, technical procedure." 49 The saxophonist's own words challenge this priority.

Coltrane's inextricable ties to the social can be further demonstrated through a consideration of his evocation of black spirituality in his later work. Even without recourse to Coltrane's liner notes for the album A Love Supreme, the listener is struck not only by the spirituality evoked but its specifically evangelical fervor. ${ }^{50}$ Moreover, as Lewis Porter has demonstrated, Coltrane made explicit use of text, the "Psalm" section of the suite containing an instrumental recitation of a poem he

${ }^{47}$ Nick Nesbitt, “Sounding Autonomy: Adorno, Coltrane and Jazz,” Telos 116 (1999), 93. On a slightly different note, the insistence on internal coherence within individual Coltrane solos needs also to be questioned. Lewis Porter tells us, "Motives and thematic ideas reappear at several points during a typical Coltrane piece, but not necessarily in a methodical manner." Lewis Porter, "John Coltrane's A Love Supreme: Jazz Improvisation as Composition," Journal of the American Musicological Society 38, no. 3 (1985): 620 .

${ }^{48}$ I have much sympathy with the Adornian notion of musical material being sedimented sociohistory. It may be that the musical work itself can tell us much more than its creators about the milieu from which it emerged. However, there is a need to acknowledge the fundamentally heteronomous nature of black expressive practices.

${ }^{49}$ Nesbitt, "Sounding Autonomy," 93.

${ }^{50}$ John Coltrane, A Love Supreme, Impulse! 589 945-2, 2002 [1965], compact disc. 
had written. Coltrane, whose maternal grandfather was a minister of the African Methodist Episcopal Zion Church, is clearly contributing to and drawing from this black spiritual tradition. Porter writes that the "roots of this solo seem to grow out of formulaic procedures used by preachers in black churches." ${ }^{11}$ We find that it is not only the content of the text that links the "Psalm" to communal concerns but also the fact that the melody is constructed to take the character of the "intonational chant" of African American preachers. Surely, this socio-aesthetic is at least as important as Coltrane's mastery of harmony on which Nesbitt focuses.

A Love Supreme is exceptional even within Coltrane's own output (although works that followed, such as "Meditations," released in 1965, show a retained interest in using music towards spiritual ends). "Giant Steps," on the other hand, does not appear to engage with socio-cultural material. Neither does it show the political commitment we hear on We Insist! Max Roach's Freedom Now Suite (featuring Abbey Lincoln) and Charles Mingus's "Fables of Faubus," both released in 1960, the same year as Giant Steps (the album on which "Giant Steps" appears). ${ }^{52}$ In fact, Coltrane's concerns about only being able to "make the changes" were, arguably, well founded, the legacy of "Giant Steps" being as a master study in jazz harmony. And yet, despite the considerable challenge identifying the extramusical within the piece, the fact that Coltrane highlights what for him is a conspicuous absence of a "black story" suggests that this social and communal material is significant. Traditionalists' idea of the story as the skillfully executed solo most often fails to address what Coltrane considered lacking in his attempts. On this point, Iyer writes:

From his concern that he isn't "tellin' no story," it is easy to suppose that Coltrane was thinking along these lines, trying to create a "coherent," Schulleresque narrative arc over the scope of a given saxophone solo. However, his hint at larger concerns of culture connection ("tellin' them black stories") suggests that his intentions transcend the étudelike nature of this clear harmonic progression, and even rise above this compositional idea of coherence. With these four words he seems to reach for musical statements in which no less than his whole community could hear its inexhaustible narrative multiplicity reflected. ${ }^{53}$

The exchange between Coltrane and his band is important in showing that "tellin' them black stories" by making music that spoke to and of a broader social and communal aesthetic, was an important measure of success for them.

\section{Layering, Listening, Mimesis}

\section{Layering and Heterophony}

In the epigraph at the start of this essay, Benjamin speaks of the way a community, that is, a communal listener whose attention sometimes spans centuries, is party to a slowly perfecting story, of which new aspects are revealed with each further con-

${ }^{51}$ Porter, "John Coltrane's A Love Supreme," 613.

52 "Fables of Faubus" appears on Charles Mingus Presents Charles Mingus in 1960, complete with defamatory lyrics. It was first recorded (without the vocal) for the album Mingus Ah Um, released in 1959.

${ }^{53}$ Iyer, "Exploding the Narrative," 394. Emphasis added. 
tribution. This framework of analysis bears a resemblance to, and indeed, overlaps with a wealth of aesthetic texts concerned with repetition in black expression. ${ }^{54}$ Benjamin's formulation provides a sustained and thought-provoking lifecycle sketch of a story's re-telling as well as a broader model of a slowly unfolding, never-tobe-completed, communal storytelling practice. “The Storyteller” sheds new light on the now commonplace concerns with repetition, versioning, or layering, and it offers a way to a clearer understanding of principles of structuration in storytelling (and, I argue, in jazz). These principles have to do with the creative tensions involved in re-telling and "playing along" without forfeiting personal distinction (one's own voice). The story is at once "already there" and slowly revealed. ${ }^{55}$ It is hard to imagine younger contributors (storytellers or musicians) free from the influence of their predecessors, and so we should expect a certain degree of dialecticism.

Yet the "piling one on top of the other of thin, transparent layers" 56 of a story points to a retention of a multitude of renditions and speaks of a parity between "versions" most often absent from teleological models of development. Henry Louis Gates highlights retention in his discussion of Jelly Roll Morton's performance of "Maple Leaf Rag." He writes, “Morton's composition does not 'surpass' or 'destroy' [Scott] Joplin's; it complexly extends and tropes figures present in the original." 57 The story presents a complex of repetitions that can be seen as a sort of concertinaed heterophony. We can imagine transparent re-tellings collapsed one on top of the other belonging to a single piece of music that is being slowly revealed. Extended, the lineage of versions resembles the notion of tradition we are most familiar with-a chronology that links the earliest renditions to more recent ones, often emphasizing development and areas of consistency. Pavlić writes of black literature, "previous versions and voices sound in the present while aligning alternative versions of the 'past' in an accumulated repertoire." 58 The very same can be said of jazz.

\footnotetext{
${ }^{54}$ There is a plethora of accounts, including James Snead's (1981) "On Repetition in Black Culture," various texts from Amiri Baraka, and of course Monson's work, particularly "Riffs, Repetition, and Theories of Globalization" (1999). Norman Weinstein's (1997) under-appreciated essay on the Art Ensemble of Chicago, "Steps Toward an Integrative Comprehension of the Art Ensemble of Chicago's Music," is also important.

${ }^{55}$ I have in mind here both Adorno's 1928 essay "Schubert" and James Snead's mischievous corroboration of Hegel's thesis regarding the sub-Saharan African remaining outside history. Snead highlights the racism implied in Hegel writing the African out of world history, while suggesting that the philosopher inadvertently points to a useful alternative to his teleological epistemology, and one, perhaps, better suited to understanding black expression. He writes, provocatively, "Hegel was almost entirely correct in his reading of black culture. ... The African, first, overturns all European categories of logic. Secondly, he has no idea of history or progress ... Finally, he is 'immediate' and intimately tied to nature with all its cyclical, non-progressive data. Having no self-consciousness, he is 'immediate' i.e., always there in any given moment. Here we can see that, 'being there,' the African is also 'always already there,' or perhaps 'always there before,' whereas the European is headed there or, better, 'not yet there"” "“On Repetition in Black Culture." Black American Literature Forum 15, no. 4 [1981]: 148).

${ }^{56}$ Benjamin, "The Storyteller," 92.

${ }^{57}$ Gates, Signifyin' Monkey, 63, emphasis in original. This quotation shows that for Gates, signifying has as much to do with collaborative accumulation of material as with subversion.

${ }^{58}$ Edward Pavlić, Crossroads Modernism: Descent and Emergence in African-American Literary Culture (Minneapolis: University of Minnesota Press, 2002), 24.
} 
When the versions are imagined as collapsed, one on top of the other, we hear something like the chorus William Francis Allen describes in the epigraph at the start of the essay. We hear "the 'basers' [members of the chorus] ... seem[ing] to follow their own whims, beginning when they please and leaving off when they please [helping to complete each other's ideas], striking an octave above or below ... or hitting some other note that chords, so as to produce the effect of a marvelous complication and variety." 59 This imagined "totality" of versions being sounded together, corresponding to one another but remaining distinct, would present us with a cacophonic complexity, not only rich in discrete detail but one in which each re-telling is cast in the refracting light of those with which it lies. This is a markedly different notion of storytelling in jazz than that which focuses on individual solos. Martin Williams's narrative of problem solving jazz greats whose rhythmic innovations "surpass" and supplant those of their predecessors, and the linear coherence much prized by Gunther Schuller are, to an extent, contained in the heterophonic model, but their linear approaches fail to reciprocate it. ${ }^{60}$

The story as presented in this article rests on principles of repetition and incompletion. A storyteller will reach the end of a performance, but the nature of the form is such that the story is kept alive by the expectation of future renditions that is encoded in it. Storytelling is a communal enterprise, and no one teller is able to satisfactorily present all. The collected experiential (and, in jazz's case, musical) fingerprints of collaborators give the story its vintage. ${ }^{61}$ Stories are open ended and are told in a manner that will allow them to be repeated by other tellers. These prospective tellers will inevitably light up novel vistas of the tale purely due to the particularity of their experience and storytelling tools (instrumental and technical limitations and advantages, for example). Moreover, we find that the open-endedness and incompletion of the story fosters an environment in which these various contributions can coexist.

Indeterminacy and the active nurture of distinction are crucial to understanding communal collaborations that emerge from these forms. It is not merely a story's orality, its being passed on from mouth to mouth, that is important, but the fact that it allows for, indeed demands, the individual expressive qualities of those mouths. The way the storyteller tells the story is not something added after the story has been constructed. Their expression, their particular way of delivering the story (its urgency or lethargy), whether they meander in loquacious verbosity or whether the story is shot out in clipped bullet points, is absolutely integral to the words, phrases and sentences used. Moreover, the playful tension involved in re-telling a communal work in his or her own voice and within his or her communicative capabilities is the prime site of creative activity. Benjamin's storyteller presents us with a model

\footnotetext{
${ }^{59}$ Quoted in Shane White and Graham White, The Sounds of Slavery: Discovering African American History Through Songs, Sermons, and Speech (Boston: Beacon, 2005), 64.

${ }^{60}$ Martin Williams, The Jazz Tradition; Gunther Schuller, "Sonny Rollins and the Challenge of Thematic Improvisation," 6-11.

${ }^{61}$ I am making reference to Walter Benjamin's description of how "traces of the storyteller cling to the story the way the handprints of the potter cling to the clay vessel" (Benjamin, "The Storyteller," 91).
} 
for expressive forms whose formative or "unity-constitutive" moment is actually mimetic in nature.

The Benjaminian formulation of mimesis bears little resemblance to what we find in Plato's disparagement of arts-the second order reproduction of the Idea or reality. Benjamin's twentieth century renovation of Aristotle's retrieval of the arts (and mimesis) presents mimesis as best understood as an "inclination" or "attitude" rather than a resultant reproduction (whether copy or "original"). ${ }^{62}$ A mimetic approach is an empathetic attitude, and one in which the parties involved approach or adapt to each other in a manner that supports the retention of their particularities. ${ }^{63}$ Here a subject can show affinity with another without being dominated or having to deny difference. There is a yielding by both parties, but the retention of difference is always in the foreground of their relations. Mimesis can show how understanding can be made without the need to hack off aspects that fail to fit what we already know. Encountering collaborative creation such as we see in storytelling and in jazz, we are shown "mimetic comportment" in action: a "sensuously receptive, expressive and communicative mode of behavior between living beings who intimately adapt to each other." 64

It can be argued, then, that the challenge of artistic creation in jazz is to find the means to retell (often) established stories or mascons and to play along in a manner that retains one's particular features and idiosyncrasies. The work is in developing technique, a way of communicating (responding and playing along with), which also allows one to retain personal distinction. The play between the musician and the collective to which he or she belongs, that is, the creative tension that occurs through demanding that an individual retain their voice as they engage in communal work, is key. ${ }^{65}$ This is by no means to suggest a static, unreflective position to which the musician stubbornly clings. As will be discussed below, the listening, and pedagogical, experience of jazz is crucial to the formation of a musician's signature. However, it is being argued here that the productive tension between the nurture of personal distinction and commitment to communal work is a creative catalyst and, in itself, an important story to be told.

\footnotetext{
${ }^{62}$ Mimesis as used by Benjamin and Adorno is notoriously difficult to understand, and its interpretation by subsequent scholars tends to add to the confusion. However, Bed Paudyal's identification of five ways Adorno used mimesis is useful for orientation. In Adorno's Aesthetics of Music, Max Paddison appears to lean towards the more anthropological connotations, presenting it as a version of mimicry, an adaptation to the hostile environment as a form of protection. However, in a more carefully considered recent essay, "Mimesis and the Aesthetics of Musical Expression," he comes much closer to the reading presented here (Music Analysis 29, no. 1-3 (2010): 134-35). See also Gary Peters, The Philosophy of Improvisation (Chicago: University of Chicago Press, 2009). This recent account of mimesis in improvised music is far the most engaged, although he perhaps overstates (and confuses) the case when he writes, "Adorno's aesthetic theory promotes a mimeticism that ... has nothing whatever to do with imitating or copying that which is already given" (86). Nevertheless, the processual dimensions and ethical connotations of the concept are effectively emphasized.

${ }^{63}$ See also Vijay Iyer, "Improvisation, Temporality and Embodied Experience," Journal of Consciousness Studies 11, no. 3-4 (2004): 159-73.

${ }^{64}$ Albrecht Wellmer, quoted in Max Paddison, "Mimesis," 139.

${ }^{65}$ What is being suggested needs to be distinguished from the liberal democratic ideal of individuals doing what they please as long as they ensure not to impinge on the freedom of others.
} 


\section{Empathetic Communication-The Listener-Collaborator}

In jazz performance the distinctive characteristics of a musician play a prominent role in the making of work. A musician's disposition, the limitations and assets of physicality and experience (both musical and otherwise), guide their approach to the musical material. Their personal quirks often provide unmistakable identification. Idiosyncrasy is a hallmark of jazz "interpretation." Although Coltrane's "Body and Soul" is retelling the standard, the gap bridged in his performance is not from the score, or from any original idea contained in the Johnny Green composition. ${ }^{66}$ "Body and Soul" the standard does not coincide with the composition of the same name. It takes in the original melody and lyrics but most importantly refers to the plethora of contribution from Louis Armstrong and his orchestra in 1930 through to Cassandra Wilson's 1991 rendition and beyond. ${ }^{67}$

"Body and Soul" is best viewed as a site of "massive concentration" of significance that is amplified with each re-telling. ${ }^{68}$ In it is contained Chu Berry and Roy Eldridge's exploration of its emotive connotations (Berry's mournful opening shredded by Eldridge's double-time romp); Dexter Gordon's characteristic mining of associative meaning taking in the lyrical themes of lost love and the body as well as melodic fragments from "Giant Steps"; Holiday's molding of the words "body and soul"; Eddie Jefferson's vocalese tribute to Coleman Hawkins; the 1969 Archie Shepp version that appears to play on the absurd sentimentality of the standard's lyrics, slipping out of the overblown romance into a sublimity that is also tugged upon; Betty Carter's almost inert "Body and Soul/Heart and Soul" medley, and many other contributions. ${ }^{69}$

There is an imperative in jazz to play a standard — that is, to tell the story—within one's own particularities, both physical and perspectival. A musician uses the tools at hand, often turning apparent limitations to advantage. An example can be heard in a Charles Mingus performance of "Sophisticated Lady," another much-played ballad. In this duet at Cornell University, the double bassist takes the melody while

${ }^{66} \mathrm{I}$ am thinking of the version recorded for the 1964 album Coltrane's Sound (recorded in 1960), but of course, the same would apply to any other. We may consider this performance as a re-composition while still allowing it to also be a retelling of the standard or a contribution to the site of "massive concentration" that is "Body and Soul."

${ }^{67}$ See Bowen's "Who Plays the Tune in 'Body and Soul'?"

${ }^{68}$ Although he would object to the connection, this concept calls to mind Adorno's idea concerning a performance of a modern European work always falling short because it will fail to include all the possible connotations contained in it. Does Coltrane's interpretation of "Body and Soul" create, that is, add to the original work? Adorno might have argued that Coltrane's work was already contained in the Idea of the piece, although I am inclined to treat the work in jazz as an activity. It may become reified in recordings, and this work does congregate at sites of significance such as "Body and Soul," but it tends not to rest in the kinds of "work-things" on which Adorno's analysis focuses. For similar perspective, see Andrew Kania, “All Play and No Work: An Ontology of Jazz," The Journal of Aesthetics and Art Criticism 69, no. 4 (2011): 391-403.

${ }^{69}$ Chu Berry and His Little Jazz Ensemble, Chu Berry-1937-1941, Classics 784, 1994, compact disc; Dexter Gordon, Nights At The Keystone Volume 3, Blue Note CDP 794850 2, 1990 [1978], compact disc; Billie Holiday, Body and Soul, Verve 314589 308-2, 2002 [1957], compact disc; Eddie Jefferson, Body and Soul, Prestige UCCO-9477, 2008, compact disc; Coleman Hawkins, Body and Soul, Victor Records/RCA 09026685152, 1996, compact disc; Archie Shepp, Yasmina: A Black Woman, Charly Records Le Jazz CD 51, 1996 [1969], compact disc; Betty Carter, Betty Carter at the Village Vanguard, Bet-Car/MK 1001, 1970, LP. 
Jaki Byard accompanies him on piano. ${ }^{70}$ Mingus was by most accounts a bass virtuoso, yet the timbre and register of the instrument makes its role as soloist particularly challenging. The double bass mumbles and groans, but it is also able to chuckle, twitter, and scream. Mingus, aided by his considerable abilities as a vocalist, tailor-makes an approach that plays to these qualities. Along with a display of dexterity across the range of the instrument, he utilized vocal-like articulation, juxtaposing his bebop with blues-imbued speech that, perhaps, is closer to his vocal work than what an instrument most often has to offer. ${ }^{71}$ Both the limitations and the tools that Mingus had nurtured shaped his contributions.

Alongside the "homemade" technique" that musicians develop, lived experience, both personal and communal, plays a central role. ${ }^{72}$ This point may appear somewhat banal. We expect works to be reflective of their authors. Yet, this experiential fingerprint is a central concern in creating jazz work. A modern European composer (and indeed performer) will imbue the piece with their character, even if the intention is to the contrary. However, for the jazz musician the retention of this distinction is the focus of the creative process rather than a (tolerated or embraced) byproduct. For Iyer, this is perhaps the most interesting of all the stories we find in jazz. He writes, "Musicians tell their stories, but not in the traditional linear narrative sense; an exploded narrative is conveyed through a holistic musical personality or attitude. ... Kinesthetics, performativity, personal sound, temporality-all these traces of embodiment generate, reflect, and refract stories into innumerable splinters and shards. Each one of these fragments is 'saying something."'73 It could be argued that the most satisfying performances often display competence in "making the changes" and exhibit high levels of technical ability, but they will always allow the musician's own way of doing things to be brought to the fore. ${ }^{74}$ As Benjamin writes of storytelling, "traces of the storyteller cling to the story the way the handprints of the potter cling to the clay vessel." 75

Borrowing from Benjamin, it can be argued that the standard is sunk "into the life of the storyteller, in order to bring it out of him again." This two-way movement is crucial, and in a sense considering experience and the communicating of experience separately is misleading. Benjamin writes, "the more completely [the story is] integrated into [the listener's] own experience, the greater will be his inclination to repeat it to someone else someday, sooner or later." This integration needs to be understood not metaphorically, but corporeally and pedagogically — the

${ }^{70}$ Charles Mingus (with Eric Dolphy), "Sophisticated Lady," On Cornell 1964, Blue Note 09463 9221028,2007 [1964], compact disc.

${ }^{71}$ Eric Dolphy, when on bass clarinet, tends to use a similar mixture of his idiosyncratic bebop and vocal articulation. It is interesting to contrast this technique with what he uses on flute.

${ }^{72}$ Jessica Williams, referring to Thelonious Monk's technique. See "Thelonious Sphere Monk," Jessica Williams—Currents (personal website, March 1998), http://www.jessicawilliams.com/ currents/monk.html.

${ }^{73}$ Iyer, "Exploding the Narrative," 402.

${ }^{74}$ Technique is a tricky word to use here, as in a sense technique is the key, but it is the "homemade" variety that is of importance. Technical ability should also include the ways of effectively contributing while playing to (and with) one's strengths and limitations.

${ }^{75}$ Benjamin, "The Storyteller," 91. 
way to become a jazz player is to immerse yourself in it. ${ }^{76}$ The storyteller and the jazz musician are listeners. Benjamin writes that "he listens to the tales in such a way that the gift of retelling them comes to him all by itself." ${ }^{\prime 77}$ And this calls to mind the often-quoted anecdote concerning Charlie Parker's apprenticeship. The saxophonist apparently spent months listening and playing along to Lester Young $78 \mathrm{~s}$. He is reported to have "played them white" through repeated listens and would alter the speed of the turntable on which they were played, transforming Young's languid tenor into a tone resembling the effervescence of Parker's alto. ${ }^{78}$ Similarly, pianist and educator Lennie Tristano would insist on his students being able to sing along to improvisations as the primary part of their training. Students tell of being encouraged to spend as much time as was necessary listening to jazz recordings, not only, or even primarily, to learn the melody and harmony of a piece, but in order to "get inside the head" of the musician and "live the solo."79 Through listening, the music becomes the musician's own. And this listening experience is an important story to be shared. ${ }^{80}$

The challenge of jazz is to find ways to share in storytelling, to play along, and repeat (often) established stories. The work is in finding ways to participate in the tradition in a manner that allows fidelity to one's own particularities. There is significant productive tension between wanting to tell the story and wanting to tell it in one's own voice. Negotiation of a desire to share in the tradition and the imperative to remain distinct is where the work of a jazz musician is centered. This mimetic attitude is a feature of all artistic pursuit, but it comes into sharp focus when considering the story and jazz. In fact, it may be that in oral traditions this mimetic negotiation is a definitive aspect of construction. ${ }^{81}$ The mimetic negotiations in jazz, storytelling, and other collaborative practices may also be their "unity-constitutive" moments. "The Storyteller," although written as a retrospective account (a mourning) of a dying oral practice, has been shown to be of use for gaining a deeper understanding of the collaborative, inter-generational nature of jazz music creation. Benjamin shows that what is being shared in storytelling are not mere words, objectively reported happenings, but experience. "The storyteller takes what he tells from experience- his own or that reported by others. And he in turn makes it the experience of those who are listening to his tale." 82 Indeed, contained in the directive "tell your story" is the assumption that jazz musicians will share the tradition as their own.

\footnotetext{
${ }^{76}$ Listening to jazz, particularly for musicians and other contributors, seems to require both the absorption Benjamin prescribes and what Adorno describes as "structural listening."

${ }_{77}$ Benjamin, "The Storyteller," 91.

${ }^{78}$ John Robert Brown, A Concise History of Jazz (Pacific, MO: Mel Bay, 2010), 100.

${ }^{79}$ Eunmi Shim, Lennie Tristano: His Life in Music (Ann Arbor: University of Michigan Press, 2007), 135.

${ }^{80}$ There is interesting work to be done exploring Benjamin's storytelling listener alongside Adorno's structural and regressive listener. Keeping in mind the retrospective from which Benjamin brings us the portrait of the storyteller, his work provides an important alternative to Adorno's stratification of listening types.

${ }^{81}$ By construction I mean the aspect of making art that is usually associated with rational thought.

${ }^{82}$ Benjamin, "The Storyteller," 87.
} 


\section{References}

\section{Books and Articles}

Adorno, Theodor. Towards a Theory of Musical Reproduction: Notes, a Draft, and Two Schemata. Cambridge: Polity, 2006.

Adorno, Theodor. "Schubert (1928)." 19th-Century Music 29, no. 1 (2005): 3-14.

Bakhtin, Mikhail. Dialogic Imagination: Four Essays. Austin: University of Texas Press, 1982.

Baraka, Amiri. Black Music: Essays. New York: Akashic, 2010.

(LeRoi Jones). Blues People: Negro Music in White America. 1963; reprinted New York: Harper Collins, 1999.

Beeson, Ann. "Quoting Tunes: Narrative Features in Jazz.” Collectanea 1 (1990): $1-15$.

Benjamin, Andrew. Present Hope: Philosophy, Architecture, Judaism. London: Taylor and Francis, 1997.

Benjamin, Walter. "The Storyteller: Reflections on the Works of Nikolai Leskov." In Illuminations: Essays and Reflections, ed. Hannah Arendt, trans. Harry Zohn, 83-107. London: Fontana, 1992.

Berliner, Paul. Thinking in Jazz: The Infinite Art of Improvisation. Chicago: University of Chicago Press, 1994.

Bjerstedt, Sven. "Storytelling in Jazz Improvisation: Implications of a Rich Intermedial Metaphor.” Ph.D. diss., Lund University, 2014.

Block, Steven. "Bemsha Swing': The Transformation of a Bebop Classic to Free Jazz." Music Theory Spectrum 19, no. 2 (1997): 206-31.

Borgo, David. "The Play of Meaning and the Meaning of Play in Jazz." Journal of Consciousness Studies 11, nos. 3-4 (2004): 174-90.

- Sync or Swarm: Improvising Music in a Complex Age. New York: Continuum, 2005.

Borgo, David, and Jeff Kaiser. "Configurin(g) KaiBorg: Ideology, Identity and Agency." In Proceedings of the International Conference, Beyond the Centres: Musical Avant-Gardes since 1950, Thessaloniki, Greece, 1-3 July 2010.

Bowen, José Antonio. "Who Plays the Tune in 'Body and Soul'?: A Performance History Using Recorded Sources." Journal of the Society for American Music 9, no. 3 (2015): 259-92.

Brown, John Robert. A Concise History of Jazz. Pacific, MO: Mel Bay, 2010.

Brown, Leonard. "In His Own Words." In John Coltrane and Black America's Quest for Freedom, ed. Leonard Brown, 11-32. New York: Oxford University Press, 2010.

Daniels, Douglas Henry. "Lester Young: Master of Jive." American Music 3, no. 3 (1985): 313-28.

DeVeaux, Scott. The Birth of Bebop a Social and Musical History. Berkeley: University of California Press, 1997.

Floyd, Samuel. The Power of Black Music: Interpreting its History from Africa to the United States. New York: Oxford University Press, 1995.

Folio, Cynthia, and Alexander Brinkman. "Dexter Gordon's Ultimate 'Body and Soul." In Five Perspectives on "Body and Soul" and Other Contributions to Music 
Performance Studies, ed. Claudia Emmenegger and Oliver Senn, 45-60. Proceedings of the "International Conference on Music Performance Analysis," Lucerne, Switzerland, 1-2 July 2009. Zurich: Chronos, 2011.

Gates, Henry Louis, Jr. The Signifying Monkey: A Theory of Afro-American Literary Criticism. New York: Oxford University Press, 1988.

Harker, Brian. Louis Armstrong's Hot Five and Hot Seven Recordings. New York: Oxford University Press, 2011.

Henderson, Stephen. Understanding the New Black Poetry: Black Speech and Black Music as Poetic References. New York: William Morrow, 1973.

Holbrook, Morris. Playing the Changes on the Jazz Metaphor an Expanded Conceptualization of Music, Management, and Marketing-Related Themes. Boston: Now Publishers, 2008.

Iyer, Vijay. "Exploding the Narrative in Jazz Improvisation." In Uptown Conversation: The New Jazz Studies, ed. Robert G. O'Meally, Brent H. Edwards, and Farah Jasmine Griffin, 393-403. New York: Columbia University Press, 2004.

. "Improvisation, Temporality and Embodied Experience." Journal of Consciousness Studies 11, no. 3-4 (2004): 159-73.

Kania, Andrew. "All Play and No Work: An Ontology of Jazz." The Journal of Aesthetics and Art Criticism 69, no. 4 (2011): 391-403.

McClary, Susan. Conventional Wisdom: The Content of Musical Form. Berkeley: University of California Press, 2000.

McKay, Nellie. "Biography and Afro-American Culture.” In Afro-American Literary Study in the 1990s, ed. Houston Baker and Patricia Redmond, 194-224. Chicago: University of Chicago Press, 1989.

Monson, Ingrid. "Doubleness and Jazz Improvisation: Irony, Parody, and Ethnomusicology." Critical Inquiry 20, no. 2 (1994): 283-313.

_. "Riffs, Repetition, and Theories of Globalization." Ethnomusicology 43, no. 1 (1999): 31-65.

- Saying Something: Jazz Improvisation and Interaction. Chicago: University of Chicago Press, 1996.

Nesbitt, Nick. "Sounding Autonomy: Adorno, Coltrane and Jazz.” Telos 116 (1999): 81-98.

Oakland, Daniel. "Remembering in Jazz: Collective Memory and Collective Improvisation." Lambda Alpha Journal 28 (1998): 16-27.

O’Meally, G. Robert. "Response to Nellie McKay's 'Biography and Afro-American Culture." In Afro-American Literary Study in the 1990s, ed. Houston Baker and Patricia Redmond, 219-224. Chicago: University of Chicago Press, 1989.

Paddison, Max. "Mimesis and the Aesthetics of Musical Expression." Music Analysis 29, no. 1-3 (2010): 126-48.

—. Adorno's Aesthetics of Music. Cambridge: Cambridge University Press, 1993.

Patke, Rajeev. "Benjamin on Art and Reproducibility: The Case of Music.” In Walter Benjamin and Art, ed. Andrew Benjamin, 278-84. London: Continuum, 2005.

Paudyal, Bed. "Mimesis in Adorno's Aesthetic Theory." Journal of Philosophy: A Cross-Disciplinary Inquiry 4, no. 8 (2009): 1-10. 
Pavlić, Edward. Crossroads Modernism: Descent and Emergence in African-American Literary Culture. Minneapolis: University of Minnesota Press, 2002.

Peters, Gary. The Philosophy of Improvisation. Chicago: University of Chicago Press, 2009.

Porter, Lewis. "John Coltrane's A Love Supreme: Jazz Improvisation as Composition." Journal of the American Musicological Society 38, no. 3 (1985): 593-621.

Reinholdsson, Peter. Making Music Together: An Interactionist Perspective on SmallGroup Performance in Jazz. Uppsala: Uppsala University Press, 1998.

Rinzler, Paul. "Preliminary Thoughts on Analyzing Musical Interaction among Jazz Performers.” Annual Review of Jazz Studies 4 (1988): 153-60.

Sawyer, Keith. "Improvisational Cultures: Collaborative Emergence and Creativity in Improvisation." Mind, Culture, and Activity 7, no. 3 (2000): 180-85.

Schuller, Gunther. Musings: The Musical Worlds of Gunther Schuller. New York: Oxford University Press, 1989.

—. "Sonny Rollins and the Challenge of Thematic Improvisation." Jazz Review 1, no. 1 (1958): 6-11.

- The Swing Era: The Development of Jazz, 1930-1945. New York: Oxford University Press, 1991.

Seddon, Frederick. "Modes of Communication during Jazz Improvisation." British Journal of Music Education 22, no. 1 (2005): 47-61.

Shim, Eunmi. Lennie Tristano: His Life in Music. Ann Arbor: University of Michigan Press, 2007.

Solis, Gabriel. "Hearing Monk: History, Memory, and the Making of a 'Jazz Giant.'” Musical Quarterly 86, no. 1 (2002): 82-116.

Snead, James. "On Repetition in Black Culture." Black American Literature Forum 15, no. 4 (1981): 146-54.

Weinstein, Norman. "Steps Toward an Integrative Comprehension of the Art Ensemble of Chicago's Music.” Lenox Avenue: A Journal of Interarts Inquiry 3 (1997): 3, 5-11.

White, Shane, and Graham White. The Sounds of Slavery: Discovering African American History Through Songs, Sermons, and Speech. Boston: Beacon, 2005.

Williams, Jessica. “Thelonious Sphere Monk.” Jessica Williams—Currents (personal website, March 1998). http://www.jessicawilliams.com/currents/monk. html.

Williams, Martin. The Jazz Tradition. New York: Oxford University Press, 1993.

\section{Recordings}

Berry, Chu, and His Little Jazz Ensemble. "Body and Soul.” Chu Berry, 1937-1941. Classics Records. Classics 784, 1994, CD.

Carter, Betty. "Heart and Soul/Body and Soul." Betty Carter at the Village Vanguard. Bet-Car Productions. MK 1001, 1970, LP.

Coltrane, John. "Body and Soul.” Coltrane's Sound [1964].Atlantic Jazz Masters. Atlantic 8122-73754-2, 2000, CD.

- Heavyweight Champion: The Complete Atlantic Recordings. Rhino Homemade. RHM1 7784, 2000, CD. 
A Love Supreme [1965].Impulse! 589 945-2, 2002, CD.

Gordon, Dexter. "Body and Soul." Nights At The Keystone Volume 3 [1978].Blue Note Records. CDP 7 94850-2, 1990, CD.

Hawkins, Coleman. "Body and Soul." Body and Soul. Composed by Johnny Green. Victor Records/RCA 09026685152, 1996, CD.

Holiday, Billie. "Body and Soul." Body and Soul [1957].Verve 314589 308-2, 2002, CD.

Jefferson, Eddie. "Body and Soul." Body and Soul [1968].Prestige UCCO-9477, 2008, CD.

Shepp, Archie. "Body and Soul." Yasmina: A Black Woman [1969].Charly Records. Le Jazz CD 51, 1996, CD. 